\title{
On measuring the frequency-difference limen for short tones
}

\author{
W. M. HARTMANN, BRAD RAKERD, and THOMAS N. PACKARD \\ Michigan State University, East Lansing, Michigan
}

\begin{abstract}
The standard deviation of the distribution of matching frequencies in a two-interval pitchmatching experiment and the width of the psychometric function in a two-interval frequencydiscrimination experiment both provide measures of the frequency-difference limen (DL). We compared DLs as measured by these two methods for tones of short duration, using all nine pairings of durations 12,25 , and $50 \mathrm{msec}$, at nominal frequencies of $200,342,584$, and $1000 \mathrm{~Hz}$. We found that the two experiments gave qualitatively different results. In frequency discrimination, the DL decreased as the duration of either the standard or the comparison tone increased, as expected from statistical decision theory in one dimension. In pitch matching, the DL was smallest whenever the standard and comparison tones had equal durations. To explain this dichotomy, we suggest that, for tones of short duration, a pitch-matching experiment permits a multidimensional comparison of two tones, but that a frequency-discrimination experiment forces a comparison along a single perceptual dimension.
\end{abstract}

Frequency-difference limens for human listeners have been measured by the method of pulsed-sine frequency discrimination (e.g., Harris, 1952) and by the method of adjustment, or pitch matching (e.g., Liang \& Chistovich, 1961). In the first method, the listener makes a forced choice, usually as to which of two tones has the higher pitch, and the frequency difference between the tones for which performance meets some criterion, for example, $75 \%$ correct, serves as the measure of the frequency-difference limen (DL). In the second method, the listener hears a target tone of given frequency and then adjusts the frequency of a second tone to match the pitch of the target. The standard deviation of the frequencies adjusted by the listener serves as a measure of the frequency DL. Of particular methodological interest are Cardozo's (1965) and Wier, Jesteadt, \& Green's (1976) studies, in which these two methods were compared. In both studies, the frequency DLs measured by the frequency-discrimination method were found to be larger than those measured with the pitch-matching method, usually by a factor of about two.

The present study compared the frequency-discrimination method with the pitch-matching method for determining frequency DLs for the interesting case of tones of short duration, in which the DLs can be rather large. In previous work on the frequency DL of short tones, often discussed in terms of the uncertainty of the pitch sensation, the two tones to be compared have had the same duration and the same amplitude envelope (e.g., Liang

This work was supported by the National Institutes of Health. B. Rakerd is in the Department of Audiology and Speech Sciences and T. N. Packard is in the Department of Psychology, both at Michigan State University. Correspondence and reprint requests should be addressed to W. M. Hartmann, Department of Physics, Michigan State University, East Lansing, MI 48824.
\& Chistovich, 1961; Majernik \& Kaluzny, 1979; Moore, 1973; Rajcan, 1972; Ronken, 1970). In the present study, considerable emphasis was placed on the case in which the tones to be compared had different durations. We suspected that differences in strategies used by listeners in the discrimination task vis-à-vis the matching task might be revealed in cases in which the durations of the two tones were different. Furthermore, one-dimensional statistical decision theory, as applied to frequency discrimination by Sekey (1963) and Siebert (1968), makes a clear prediction about the relationship between the DL for tones of unequal duration and the DL for tones of equal duration. By comparing DLs for equal and unequal tone durations we would be able to test this prediction.

\section{PITCH-MATCHING EXPERIMENT}

\section{Subjects}

\section{Method}

Four subjects participated in this experiment. All of them had normal hearing according to self-report. Two of the subjects (A and L) had had recent extensive experience in matching the pitches of short tones. Two of the subjects (B and T) were coauthors.

\section{Procedure}

The subject's task was to adjust the frequency of a matching tone so as to make its pitch agree with that of a target tone. The target and matching tones of each trial alternated indefinitely until the subject was satisfied with his match. There was a $500-\mathrm{msec}$ delay between target and matching tones and a 750-msec delay between repetitions. Four target-tone frequencies were used: $200,342,584$, and $1000 \mathrm{~Hz}$.

An experimental run comprised 12 matching trials. Within a run, the duration of the matching tone was fixed at 12,25 , or $50 \mathrm{msec}$. The duration of the target tone was initially set to one of these values, chosen at random and maintained there while the target-tone frequencies cycled through the four fixed values, in order of increasing frequency, from trial to trial. A second target-tone duration was then selected randomly and the cycle of target-tone frequencies began 
anew. Subjects $A, B$, and $L$ typically required $30( \pm 5)$ presentations before making a decision; Subject $T$ required $20( \pm 5)$. Thus, an experimental run required approximately 6 to $9 \mathrm{~min}$ to complete; this was followed by a rest period of 5 min prior to the next run. The subjects usually completed 10 runs in a testing session. The matching-tone duration was varied randomly across runs, and testing continued until each subject had completed 10 runs at each of 12,25 , and $50 \mathrm{msec}$.

\section{Stimuli}

The stimuli were sine tones from a computer-controlled oscillator (Wavetek VCG 116). These tones were presented diotically, via headphones (Yamaha YH 1000), to the subject, who was seated in a sound-treated room. The frequency of the matching tone was controlled by the subject by means of a 10-turn potentiometer with a featureless knob, 2 in. in diameter. The control was linear, and the limits of the matching frequency were set at 100 and $1200 \mathrm{~Hz}$. The frequencies were read to an accuracy of $0.01 \mathrm{~Hz}$ by a triggered clock connected to the computer that ran the experiment. All tones had abrupt onsets and offsets, both uncorrelated with the signal phase; all tones had an intensity of $70 \mathrm{~dB}$ SPL.

\section{Results}

\section{Pitch Shifts for Tones of Different Durations}

In general, the average matching frequency did not equal the corresponding target frequency because of pitch changes with duration (Doughty \& Garner, 1948; Eckdahl \& Stevens, cited in Stevens \& Davis, 1938). Such pitch shifts are not of primary interest in this work, but we examined them as a by-product. Of interest were the matches to a $25-\mathrm{msec}$ target tone made by a subject using a $12-\mathrm{msec}$ matching tone as compared with his matches to a $12-\mathrm{msec}$ target tone using a 25-msec matching tone, and similarly for the other two pairings of unequal tone durations. There were 45 such cases. ${ }^{1}$

We expected to observe a simple duration dependence: If a target tone of duration T1 was matched on the high side by a matching tone of duration $\mathrm{T} 2(\mathrm{~T} 1 \neq \mathrm{T} 2)$, then a target tone of duration $\mathrm{T} 2$ should have been matched on the low side by a matching tone of duration T1. Such a simple duration dependence was observed in 32 of the 45 cases. These cases are indicated by the symbols $S$ and $\mathrm{L}$ in Table 1.

We also observed some presentation-order effects in which the second (matching) tone consistently had a higher or lower pitch than the first (target) tone, regardless of the tone durations. ${ }^{2}$ Such effects were observed in 9 of the 45 cases, and they are indicated in Table 1 by the symbols 1 and 2 . In 4 cases, the matches with unequal durations suggested a presentation-order effect, but the sign of the shift did not agree with the signs for equal durations. Such cases were termed "inconsistent," and are indicated in Table 1 by the symbol $\mathrm{I}$.

The preponderance of the data reveals the simple duration dependence, and within that subset of the data there is considerable reproducibility, as can be seen from Table 1 . There, the symbol $\mathrm{S}$ means that when the short and long duration tones were judged to be equal in pitch, the frequency of the short tone was higher. It is reasonable
Table 1

Types of Pitch Shifts in the Pitch-Matching Experiment

\begin{tabular}{ccccc}
\hline & & \multicolumn{3}{c}{ Durations } \\
\cline { 3 - 5 } Subject & Frequency & $12 / 25 \mathrm{msec}$ & $12 / 50 \mathrm{msec}$ & $25 / 50 \mathrm{msec}$ \\
\hline T & $(\mathrm{Hz})$ & $25 / 12 \mathrm{msec}$ & $50 / 12 \mathrm{msec}$ & $50 / 25 \mathrm{msec}$ \\
& 200 & $\mathrm{~S}$ & $\mathrm{~S}$ & $\mathrm{~L}$ \\
& 342 & $\mathrm{~S}$ & $\mathrm{~S}$ & $\mathrm{~L}$ \\
& 584 & $\mathrm{~S}$ & $\mathrm{~S}$ & 2 \\
B & 1000 & $\mathrm{~S}$ & $\mathrm{I}$ & 2 \\
& 200 & 2 & $\mathrm{I}$ & $\mathrm{L}$ \\
& 342 & 2 & 2 & $\mathrm{~L}$ \\
& 584 & 2 & 2 & 2 \\
$\mathrm{~L}$ & 1000 & $\mathrm{~L}$ & $\mathrm{~L}$ & $\mathrm{~L}$ \\
& 200 & $\mathrm{~S}$ & $\mathrm{~S}$ & 1 \\
& 342 & $\mathrm{I}$ & $\mathrm{L}$ & $\mathrm{L}$ \\
& 584 & $\mathrm{~S}$ & $\mathrm{I}$ & $\mathrm{L}$ \\
$\mathrm{A}$ & 1000 & $\mathrm{~S}$ & $\mathrm{~S}$ & $\mathrm{~S}$ \\
& 200 & $*$ & $*$ & $*$ \\
& 342 & $\mathrm{~S}$ & $\mathrm{~S}$ & $\mathrm{~L}$ \\
& 584 & $\mathrm{~S}$ & $\mathrm{~S}$ & $\mathrm{~L}$ \\
& 1000 & $\mathrm{~S}$ & $\mathrm{~S}$ & $\mathrm{~L}$ \\
\hline
\end{tabular}

Note-The symbols indicate which tone had the higher frequency when two tones, of unequal duration, were judged to be equal in pitch. $S=$ shorter tone higher frequency regardless of order, $L=$ longer tone higher frequency regardless of order, $1=$ first tone higher frequency regardless of duration, $2=$ second tone higher frequency regardless of duration, $I=$ inconsistent matches.

to assume that had the frequencies of the two tones been the same, then the pitch of the short tone would have been perceived as lower than the pitch of the long tone. Therefore, the interpretation for pitch shifts of the symbol $S$ is that the shorter tone has the lower pitch.

For the shortest durations (12-25 and $12-50 \mathrm{msec})$, the data strongly suggest that a shorter tone has a lower pitch. For the longer durations of $25-50 \mathrm{msec}$, it appears that a longer tone has a lower pitch.

For those cases in which a consistent presentation-order effect was seen, the second tone was almost always tuned to a higher frequency than the first (symbol 2 in Table 1), suggesting that had the frequencies of the tones been the same, then subjects would have perceived a descending cadence.

\section{Pitch-Matching Variability}

The variability in pitch matching provides a measure of the frequency DL and is of primary interest in this study. The standard deviations (SDs) of the matching frequencies for the four subjects, four target frequencies, and six duration pairings are shown in Table 2. Values in the table are given in cents. ${ }^{3}$ Each value in the table for the equal-duration cases is based upon 10 matches. Each value in the table for the unequal-duration cases was computed by combining long-short and short-long conditions and is therefore based upon two sets of 10 matches. For unequal durations, the SD was computed as a simple average of the SDs for the long-short condition and the short-long condition. Such an average gives a smaller es- 
timate of the variability than would be given by the square root of the average variance. Nonetheless, as the table shows, the variability for unequal-duration cases tends to be considerably larger than that for equal-duration cases.

The application of one-dimensional statistical decision theory to a frequency discrimination task by Sekey (1963) and by Siebert (1968) makes a prediction which relates the DLs measured with different durations. A priori, it seems reasonable to test that prediction in the case of a pitch-matching experiment as well. If DLs determined by the matching and by the discrimination procedures are related by a scale factor (Cardozo, 1965, and Wier et al., 1976, suggest a factor of about 2), then the prediction from decision theory should apply to the matching experiment.

The prediction is simple to describe. If $\mathrm{S} 11$ is the SD of the matches when the tones that are compared both have duration T1, if S22 is the SD when both tones have duration T2, and if S12 is the SD when one tone has duration $\mathrm{T} 1$ and the other has duration $\mathrm{T} 2$, then decision theory in one dimension predicts that

$$
\mathrm{S} 12^{2}=\left(\mathrm{S} 11^{2}+\mathrm{S} 22^{2}\right) / 2
$$

Our test of this prediction was as follows: For each value of $\mathrm{T} 1$ and $\mathrm{T} 2(\mathrm{~T} 1 \neq \mathrm{T} 2)$, we computed an expected value of the SD S12 from Equation 1, based upon the observed values of S11 and S22. This is plotted on the horizontal axis in Figure 1. On the vertical axis is plotted the observed value of $\mathrm{S} 12$. If the prediction is correct, then the points on the graph should fall along the $45^{\circ}$ line. The figure clearly shows that the prediction fails. The observed values of the SD for unequal durations are greater than predicted by the one-dimensional decision theory.

Table 2

Standard Deviations of Pitch Matches Made in the Pitch-Matching Experiment

\begin{tabular}{|c|c|c|c|c|c|c|c|}
\hline \multirow[b]{2}{*}{ Subject } & \multirow{2}{*}{$\begin{array}{l}\text { Frequency } \\
\qquad(\mathrm{Hz})\end{array}$} & \multicolumn{3}{|c|}{ Equal Durations } & \multicolumn{3}{|c|}{ Unequal Durations } \\
\hline & & $12 / 12$ & $25 / 25$ & $50 / 50$ & $\begin{array}{l}12 / 25 \\
25 / 12 \\
\end{array}$ & $\begin{array}{l}12 / 50 \\
50 / 12 \\
\end{array}$ & $\begin{array}{l}25 / 50 \\
50 / 25 \\
\end{array}$ \\
\hline $\mathbf{T}$ & $\begin{array}{r}200 \\
342 \\
584 \\
1000\end{array}$ & $\begin{array}{r}27 \\
28 \\
14 \\
7\end{array}$ & $\begin{array}{r}12 \\
7 \\
9 \\
3\end{array}$ & $\begin{array}{l}5 \\
4 \\
2 \\
2\end{array}$ & $\begin{array}{l}33 \\
25 \\
14 \\
18\end{array}$ & $\begin{array}{l}52 \\
21 \\
26 \\
14\end{array}$ & $\begin{array}{r}20 \\
6 \\
4 \\
2\end{array}$ \\
\hline B & $\begin{array}{r}200 \\
342 \\
584 \\
1000\end{array}$ & $\begin{array}{l}37 \\
32 \\
10 \\
19\end{array}$ & $\begin{array}{r}13 \\
16 \\
3 \\
5\end{array}$ & $\begin{array}{r}16 \\
8 \\
5 \\
4\end{array}$ & $\begin{array}{l}81 \\
48 \\
14 \\
19\end{array}$ & $\begin{array}{r}119 \\
87 \\
47 \\
27\end{array}$ & $\begin{array}{r}32 \\
14 \\
11 \\
9\end{array}$ \\
\hline $\mathrm{L}$ & $\begin{array}{r}200 \\
342 \\
584 \\
1000\end{array}$ & $\begin{array}{r}41 \\
18 \\
7 \\
5\end{array}$ & $\begin{array}{r}37 \\
7 \\
3 \\
5\end{array}$ & $\begin{array}{r}15 \\
5 \\
2 \\
3\end{array}$ & $\begin{array}{r}41 \\
28 \\
7 \\
6\end{array}$ & $\begin{array}{r}45 \\
23 \\
12 \\
7\end{array}$ & $\begin{array}{r}45 \\
8 \\
4 \\
3\end{array}$ \\
\hline $\mathbf{A}$ & $\begin{array}{r}200 \\
342 \\
584 \\
1000\end{array}$ & $\begin{array}{r}* * * \\
19 \\
5 \\
5\end{array}$ & $\begin{array}{r}* * * \\
8 \\
2 \\
2\end{array}$ & $\begin{array}{r}* * * \\
4 \\
3 \\
1\end{array}$ & $\begin{array}{r}* * * \\
14 \\
7 \\
5\end{array}$ & $\begin{array}{r}* * * \\
12 \\
7 \\
5\end{array}$ & $\begin{array}{r}* * * \\
9 \\
3 \\
2\end{array}$ \\
\hline
\end{tabular}

Note-Values are in cents.

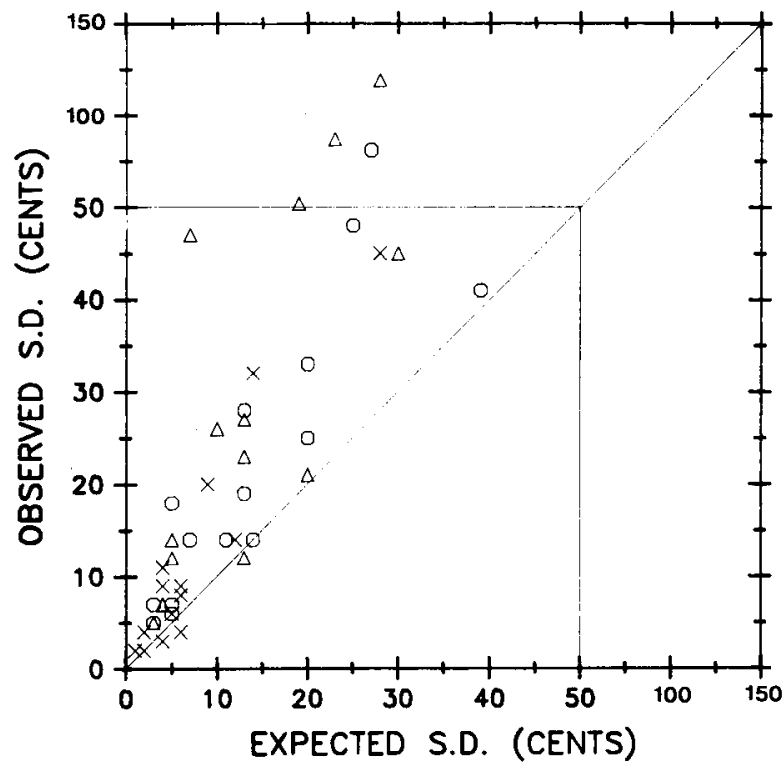

Figure 1. Pitch-matching experiment: Observed value of the standard deviation in matching frequencies for tones of unequal duration plotted against the expected value of the standard deviation based upon the standard deviations for tones of equal durations. The expectation is derived from statistical decision theory (see text). The 12-25-msec pair is represented by the octagonal symbols, the 12-50-msec pair by the triangles, and the $25-50$-msec pair by the $\times \mathbf{s}$.

\section{FREQUENCY-DISCRIMINATION EXPERIMENT}

Method
Thects subjects of this experiment were the same ones who participated in the pitch-matching experiment.

\section{Stimuli}

The stimuli were identical to those of the pitch-matching experiment, except that onsets occurred at signal zero crossings. The tones were generated digitally at a sample rate of $4000 \mathrm{~Hz}$, converted by a 12-bit DAC, and low-pass filtered (-115 dB/octave) at $1900 \mathrm{~Hz}$. The listening conditions were the same as for the pitchmatching experiment.

\section{Procedure}

The goal of this experiment was to produce a psychometric function giving the percentage of responses for which one tone was judged higher in pitch than another tone as a function of the frequency difference between the tones. The two tones were either of equal or unequal duration; in the latter case, it was always the frequency of the longer tone that varied. Unlike the pitch-matching experiment, in which the order of the different durations was fixed for a given run, the order of the different durations varied randomly from trial to trial in the frequency-discrimination experiment.

We wished to construct the psychometric function using a twointerval forced-choice (2IFC) method of constant stimuli; however, because of the pitch shifts associated with different tone durations, there was no "correct" response in the unequal-duration cases. Therefore, we needed a procedure for establishing a reasonable range for a constant-stimuli test. Our approach was to conduct a two-part experiment, employing first a staircase procedure to establish a range and then a constant-stimuli procedure to explore that 
range. As in the pitch-matching experiment, we fixed the durations of tones within an experimental run, and then cycled through the target frequencies from lowest to highest. Within a run, the twopart experiment, staircase plus constant stimuli, was done at each target frequency.

Staircase procedure. For the staircase procedure, the frequency of the longer tone (the variable) was initially chosen randomly within a range of \pm 50 cents $( \pm 3 \%)$ about the frequency of the shorter tone. The initial step size by which the frequency of the longer tone changed from trial to trial was initially chosen to be \pm 17 cents $( \pm 1 \%)$, except for the cycle at $200 \mathrm{~Hz}$, where the step size was twice as large. The staircase procedure was 2IFC, with the longer tone randomly presented first or second. The subject pressed a button to indicate which tone had the higher pitch. If the shorter tone was chosen, the frequency of the longer tone was increased by the step size. If the longer tone was chosen, its frequency was decreased by the step size. This procedure continued until the subject had reversed the staircase 15 times. The minimum and maximum frequencies for the longer tone in the final 10 staircase turns became two fixed points in the range for the constant-stimuli procedure that followed.

There were two variations included in the staircase procedure. First, 25\% of all trials were "catch" trials, randomly inserted and irrelevant to the progress of the staircase. On these trials, the frequency ratio, $f($ long $) / f$ (short), was inverted from its value on the previous trial. The purpose was to keep subjects alert during those periods of time in which the normal staircase procedure resulted in pitches for the longer tone which were al ways considerably higher or lower than the pitches for the shorter tone. (Except for the case of equal-duration tones, the two tones were always distinguishable by their durations.) The second variation allowed for the possibility of an initial staircase step size that was too large. If, after 15 turns, the maximum and minimum frequencies differed only by the step size itself, then the step size was divided by two and the staircase procedure was repeated.

Constant-stimuli procedure. In the constant-stimuli procedure, there were seven values of frequency for the longer tone$\mathrm{f} 1, \mathrm{f} 2, \ldots, \mathrm{f} 7$-determined as follows. Frequencies $\mathrm{f} 2$ and $\mathrm{f} 6$ were the minimum and maximum values from the staircase. Frequencies $f 3, f 4$, and $f 5$ were linearly interpolated (on the log scale of cents) between $f 2$ and $f 6$. Therefore, the frequency ratio for adjacent tones was

$$
r=f_{n+1} / f_{n}=\left(f_{6} / f_{2}\right)^{1 / 4},
$$

corresponding to a constant difference, in cents, of

$$
\Delta=[300 / \ln (2)] \ln \left(f_{6} / f_{2}\right)
$$

The end points, $f 1$ and $f 7$, extended beyond the staircase limits; $\mathrm{f} 1$ was set $\Delta$ cents less than $\mathrm{f} 2, \mathrm{f} 7$ was $\Delta$ cents more than $\mathrm{f} 6$. We expected that these choices of frequencies would lead to good psychometric functions, near $0 \%$ at $\mathrm{f} 1$ and $100 \%$ at $\mathrm{f} 7$, with a useful distribution at intermediate values.

The constant-stimuli procedure began immediately after the range had been established by the staircase procedure. It was actually impossible for the subject to recognize the transition between the two procedures, and there was no need to, because the task remained the same. Throughout, it was a 2IFC decision, namely, which tone had the higher pitch. There were 10 presentations at each of the constant frequencies, f $1-f 7$, in random order.

It took approximately $15 \mathrm{~min}$ to complete an experimental run (four cycles through the two-part experiment). A subject rested for approximately $5 \mathrm{~min}$ between runs and did six to eight runs in a testing session. In all, each subject completed a unique randomization of 24 runs, 4 at each of the 6 combinations of tone durations, 3 equal and 3 unequal durations.
Table 3

Widths of the Psychometric Functions Derived in the Frequency-Discrimination Experiment

\begin{tabular}{ccrrrrrrr}
\hline & Frequency & \multicolumn{3}{c}{ Equal Durations } & & \multicolumn{3}{c}{ Unequal Durations } \\
\cline { 5 - 6 } \cline { 6 - 8 } Subject & $(\mathbf{H z})$ & $12 / 12$ & $25 / 25$ & $50 / 50$ & & $12 / 25$ & $12 / 50$ & $25 / 50$ \\
\hline $\mathrm{T}$ & 200 & 99 & 34 & 12 & 77 & 96 & 26 \\
& 342 & 36 & 11 & 8 & 34 & 20 & 8 \\
& 584 & 22 & 7 & 6 & 17 & 17 & 11 \\
& 1000 & 17 & 6 & 4 & 16 & 16 & 8 \\
$\mathrm{~B}$ & 200 & 167 & 51 & 39 & 164 & 151 & 45 \\
& 342 & 30 & 20 & 27 & 28 & 70 & 24 \\
& 584 & 21 & 10 & 12 & 16 & 24 & 12 \\
& 1000 & 14 & 12 & 10 & 28 & 29 & 15 \\
$\mathrm{~L}$ & 200 & 127 & 71 & 32 & 70 & 160 & 57 \\
& 342 & 45 & 28 & 18 & 41 & 36 & 20 \\
& 584 & 15 & 8 & 6 & 15 & 16 & 8 \\
& 1000 & 46 & 11 & 9 & 16 & 12 & 8 \\
$\mathrm{~A}$ & 200 & $* * *$ & $* * *$ & $* * *$ & $* * *$ & $* * *$ & $* * *$ \\
& 342 & 82 & 20 & 14 & 31 & 21 & 14 \\
& 584 & 21 & 12 & 8 & 10 & 29 & 10 \\
& 1000 & 16 & 9 & 5 & 10 & 13 & 7 \\
\hline
\end{tabular}

Note-Values are in cents.

\section{Analysis}

The results were pooled across the four runs for each subject, for each frequency, at each duration combination. Because of the adaptive procedure used, these different runs employed slightly different values for their constant-stimulus frequencies. We therefore combined the four runs into a single data set and found the best-fitting cumulative-normal function, with $0 \%$ and $100 \%$ points discarded. Then we determined the width of this best-fit psychometric function on the scale of cents, where width was defined as half the difference between the frequencies corresponding to the $75 \%$ and $25 \%$ points of the function. ${ }^{4}$

\section{Pitch-Shift Effects}

\section{Results}

Pitch shifts were estimated from the 50\% points of psychometric functions for unequal-duration tones. The trend of these data was the same for all frequencies: at the shortest durations $(12-25,12-50 \mathrm{msec})$, the shorter tone had the lower pitch. This was true in 21 of 30 cases. For the durations $25-50 \mathrm{msec}$, the longer tone had the lower pitch in 10 of 15 cases. Thus, the trend of the shifts observed in the discrimination experiment agreed exactly with the trend observed in the matching experiment. This agreement contrasts with the results obtained by Doughty and Garner (1948), who found shifts of $1 \%$ to $2 \%$ in a matching experiment and no shifts in a discrimination experiment.

\section{Widths of the Psychometric Functions}

The widths of the psychometric functions are of primary importance in this study because these provide a measure of the DL. The widths for the frequency-discrimination experiment are shown in Table 3, which is analogous to Table 2 for the pitch-matching experiment. The values in Table 3 tend to be larger than the corresponding entries in Table 2. As expected, therefore, our data show that the DLs found in a discrimination task are larger than 
the DLs found in a matching task. In contrast to Table 2, the widths in the discrimination experiment are not notably larger when the durations of the two tones are unequal. A graph of the observed values of the width for cases of tones of unequal durations plotted against the expected values of the width, as predicted by one-dimensional decision theory, is shown in Figure 2. This plot is directly comparable to Figure 1 for the matching experiment. In contrast to Figure 1, the data for the discrimination experiment tend to lie along the $45^{\circ}$ line, or to lie above and below the line equally often, as expected, if the theory is correct.

\section{COMPARISON OF THE METHODS}

Figures 1 and 2 show that although the psychometric function widths in a discrimination experiment tend to agree with the predictions of one-dimensional decision theory, the standard deviations in a matching experiment do not. There is another prediction of the one-dimensional theory, one that does not depend upon the form of the distribution along the decision axis.

We consider an experiment in which the pitches of two tones are compared. We suppose that the durations of the two tones are the same, which is the usual case. If the duration is short, then the strength of the pitch sensation for each tone will be limited and the comparison of the two tones will be inaccurate. One-dimensional decision theory predicts that if the duration of one of the tones is

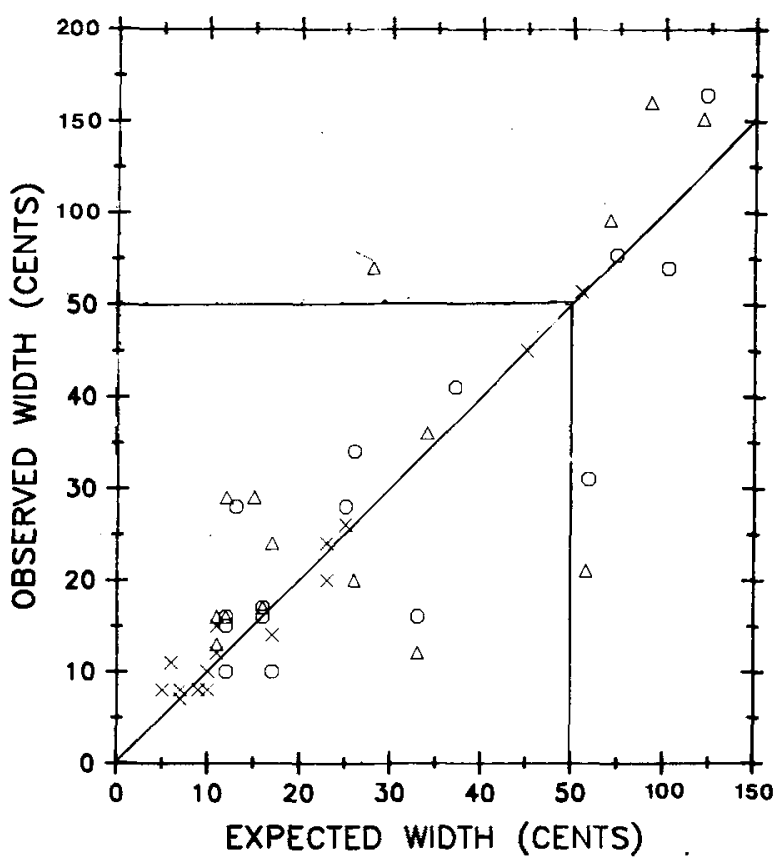

Figure 2. Frequency-discrimination experiment: Observed vaîue of the width of the psychometric function for tones of unequal duration plotted against the expected value of the width based upon the widths for tones of equal durations. The expectation is derived from statistical decision theory (see text). Symbols are the same as in Figure 1.

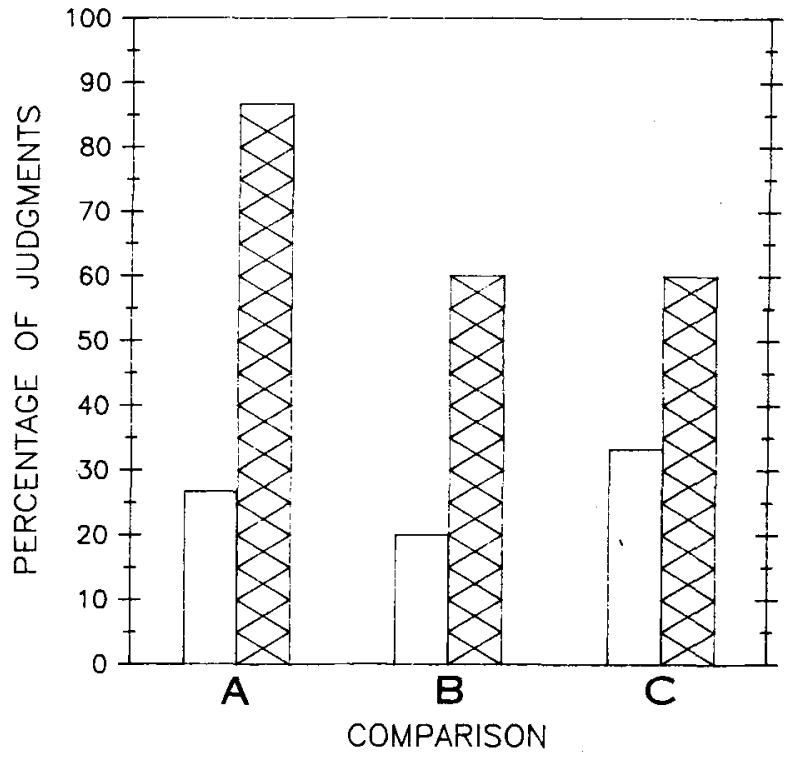

Figure 3. The ordinate shows the percentage of the judgments on pairs with durations $\mathrm{T} 1-\mathrm{T} 2$ or $\mathrm{T} 2-\mathrm{T} 1,(\mathrm{~T} 1<\mathrm{T} 2)$, in which the DL was smaller, as expected, than the DL for T1-T1. (A) The DL for 12-25 msec or 25-12 msec is smaller than for 12-12 msec. (B) The DL for 12-50 msec or 50-12 msec is smaller than for 12-12 msec. (C) The DL for 25-50 msec or 50-25 msec is smaller than for 25-25 msec. Results for the pitch-matching experiment are given by open bars. Results for the frequency-discrimination experiment are given by hatched bars.

increased, the pitch sensation for that tone will be stronger and the comparison should be more accurate.

We tested this prediction using the DLs for tones of equal and unequal durations as described above. Our data permitted three types of test. In Test A, we found the percentage of instances in which the DL for the 12-msec12-msec condition decreased when one of the tones was lengthened to $25 \mathrm{msec}$, that is, in the $12-\mathrm{msec}-$ 25-msec condition or in the 25 -msec-12-msec condition. Test B compared the 12-msec-12-msec condition with the 12-msec-50-msec and 50-msec-12-msec conditions. Test $\mathrm{C}$ compared the $25-\mathrm{msec}-25-\mathrm{msec}$ condition with the 25-msec-50-msec and the 50-msec-25-msec conditions. The results of the three tests are given by the histograms in Figure 3. A statistical test showed that the histograms for the two different experiments were significantly different $[F(1,3)=122.5, p<.001]$. The histograms show that, in most instances, the predictions of the decision theory hold for the frequency-discrimination experiment and fail for the pitch-matching experiment. The failure in Tests $\mathrm{A}, \mathrm{B}$, and $\mathrm{C}$ is actually a stronger indication that the one-dimensional theory does not apply to pitch matching than is the failure of the test shown in Figure 1, because Tests A, B, and C are arithmetically easier to pass.

Other authors have noted that the DL determined in a matching experiment tends to be smaller than the DL determined in a discrimination experiment. As Moore (1973) has noted, there is a difficulty with the discrimination task, in that the subject may notice that two tones are differ- 
ent, but be unable to say which of the two had the higher pitch. Thus, although the subject notices a pitch difference, he does not necessarily make a correct response. This difficulty does not occur in the matching task, in which the listener can readily test his conjectures as to which of the tones is higher in pitch and can also use a bracketing strategy.

To compare the DLs found in our two experiments, we computed the ratio of the width from the discrimination experiment to the SD from the matching experiment, for each subject, frequency, and duration pairing. We then took the average of those ratios and found:

For equal-duration tones:

$$
\langle(\text { Discrimination width }) /(\text { Matching } \mathrm{SD})\rangle=2.9
$$

For unequal-duration tones:

$$
\langle(\text { Discrimination width }) /(\text { Matching SD })\rangle=1.8
$$

Both ratios are greater than 1, but the ratio for equalduration tones is larger than that for unequal-duration tones. Thus, we have observed the expected advantage of matching over discrimination, but the fact that the ratio is different for equal and unequal durations suggests that there is an additional factor that operates in the case of tones of short duration.

To explain the difference, we propose that in a matching experiment with tones of equal duration, a listener actually uses several psychological dimensions. One of these dimensions is surely a sensation of tone height, a dimension that would normally be associated with pitch. Another dimension is probably one of timbre, the quality of the tone pulse. In the case of equal tone durations, the subject can adjust the frequency of the second tone so that the two tones sound identical in every respect, because the method allows him to make the tones physically identical. In the case of tones of unequal duration, however, the subject can never make the tones sound identical. The physical correlate of this is that the form of the spectral splatter for the tones is necessarily different when the tones have different durations. Our explanation continues by supposing that a discrimination experiment, in which there is only a single exposure to the tones, has the function of limiting the subject's decision space to a single perceptual dimension, probably the pitch dimension.

This explanation accounts for our data. It explains why the results of the frequency-discrimination experiment for tones of unequal duration agree with the predictions of statistical decision theory in one dimension whereas the results of the pitch-matching experiment do not. In the latter experiment, the SDs for unequal durations lie above the predicted SDs, because the predicted SDs are based upon the SDs for equal durations, which are low because the listener can use the timbre dimension. It similarly accounts for the fact that when the duration of one of the two tones is increased, so that it is longer than the other, the performance improves, as expected, for the discrimination experiment, but actually gets worse for the matching experiment. The explanation also qualitatively explains the difference between the two <Discrimination/Matching $>$ ratios above.

The different natures of the DLs determined by pitch matching and those determined by discrimination procedures have been demonstrated above only for tones of short duration. It is natural to wonder whether these differences, which we attribute to a multidimensional nature of the matching strategy, occur in the more common experiment in which the durations are long enough for DLs not to be limited by duration. On the basis of introspective listening, we suspect that the answer is that they do not occur. A tone of long duration can be turned on slowly to produce minimal spectral splatter, and hence minimal timbral cues. Even if it is turned on and off abruptly, a long tone has very compelling pitch; the transients are fleeting and are perceived as segregated from the body of the tone. A short-duration tone is quite different. The onset and offset are not distinguishable as such and are not perceived as distinct from the brief steady-state portion of the tone. The entire pulse is a single entity characterized by a pitch and a timbre. This is true regardless of the form of the amplitude envelope (see Appendix).

If the above conjecture is correct, then a pitch-matching experiment employing short tones of equal duration is a rather unique case; it is the only experiment in which the timbral dimension is of use to the listener. In that connection, it is perhaps worth noting that the ratio of $<$ Discrimination/Matching $\rangle=1.8$, which we obtained for short tones of unequal duration, is rather close to the ratio of 2, obtained by Wier et al. (1976), for long-duration tones. The ratio of 2.9 , which we observed for short tones of equal duration, is not as close, as would be expected if the timbre cue were available only in this case.

\section{CONCLUSIONS}

We have determined the frequency DL for tones of short duration by two experimental methods, pitch matching and frequency discrimination. We compared the DLs obtained for cases in which the tones had equal durations with the DLs obtained when they had unequal durations. Such a comparison is interesting because one-dimensional statistical decision theory makes a prediction for the DLs for tones of unequal duration, given the DLs for tones of equal duration. This prediction does not depend upon the physiology involved. It is the same whether one assumes that the perceptual process is based upon place of neural excitation or upon neural timing, or upon a combination of these.

We found that the results of the frequency-discrimination experiment agree with the predictions of the onedimensional theory, whereas the results of the pitchmatching experiment do not. We concluded that a pitchmatching experiment, for short tones of equal duration, permits a listener to use more than one perceptual dimen- 
sion. We suggested that both a pitch dimension and a timbre dimension are used. In the case of a frequencydiscrimination experiment, only a single perceptual dimension, probably the pitch dimension, can be used. These conclusions apply specifically to tones of short duration, in which the DL is limited by the duration of the tones.

\section{REFERENCES}

Cardozo, G. L. (1965). Adjusting the method of adjustment: SD vs DL. Journal of the Acoustical Society of America, 37, 786-792.

Doughty, J. M., \& Garner, W. R. (1948). Pitch characteristics of short tones. II-Pitch as a function of tonal duration. Journal of Experimental Psychology, 38, 478-494.

HARRIS, J. D. (1952). Pitch discrimination. Journal of the Acoustical Society of America, 24, 750-755.

Liang, Chin-AN, \& Chistovich, L. A. (1961). Frequency-difference limens as a function of tonal duration. Soviet Physics-Acoustics, 6, 75-80.

MAJERNIK, V., \& KALUZNY, J. (1979). On the auditory uncertainty relations. Acustica, 43, 132-146.

MoORE, B. C. J. (1973). Frequency difference limens for short-duration tones. Journal of the Acoustical Society of America, 54, 610-619.

RAJCAN, E. (1972). The pitch of short sinusoidal pulses as a function of initial phase. Acustica, 26, 147-152.

RONKEN, D. A. (1970). Some effects of bandwidth-duration constraints on frequency discrimination. Journal of the Acoustical Society of America, 49, 1232-1242.

SEKEY, A. (1963). Short-term auditory frequency discrimination. Joumal of the Acoustical Society of America, 35, 682-690.

SIEBERT, W. M. (1968). Stimulus transformations in the peripheral auditory system. In P. A. Kolers \& M. Eden (Eds.), Recognizing patterns (pp. 104-133). Cambridge, MA: MIT Press.

Stevens, S. S., \& DAvis, H. (1938). Hearing: Its psychology and physiology. New York: Wiley.

WIER, C. C., JesteadT, W., \& GREen, D. M. (1976). A comparison of method-of adjustment and forced-choice procedures in frequency discrimination. Perception \& Psychophysics, 19, 75-79.

\section{NOTES}

1. Four listeners $\times$ four frequency ranges $x$ three pairs of unequal durations would give 48 data points. However, one listener made very erratic matches in the $200-\mathrm{Hz}$ frequency range. His data at $200 \mathrm{~Hz}$ were excluded from this experiment and from the discrimination experiment that follows. Therefore, there are only 45 data points for this experiment.

2. An example of a consistent presentation-order effect is a case in which the frequency of the matching tone was higher than the frequency of the target tone for all of the following durations: $12-\mathrm{msec}-25-\mathrm{msec}$, 25 -msec-12-msec, 12-msec-12-msec, and 25-msec-25-msec. Such a case would be indicated by a symbol ' 2 "' in the column $12 / 25,25 / 12$ in Table 1.

3. The difference between two frequencies, $\mathrm{f} 2$ and $\mathrm{f} 1$, in cents is given by the equation: $\mathrm{C}=[1200 / \log (2)] \log (\mathrm{f} 2 / \mathrm{f} 1)$. Dividing a difference in cents by 17 gives the percent change to within $1 / 2 \%$ for differences from 0 to 200 cents.

4. Half the difference between the frequency for $75 \%$ and the frequency for $25 \%$ on the psychometric function is a reasonable choice for the frequency $D L$. Suppose that a single tone creates an excitation on an internal tonotopic coordinate, which, because of internal noise, has a normal distribution with standard deviation $\sigma$. Then a twoalternative forced-choice task will result in a psychometric function in which the difference between $75 \%$ and $25 \%$ points is given by $[f(75 \%)-f(25 \%)]=1.92 \sigma$. The reciprocal of 1.92 is very close to $1 / 2$.

5. A pattern-matching place theory predicts that a shorter tone has a lower pitch. As the duration of a tone increases, its spectrum is narrowed. Therefore, there is less excitation in neural filters with charac- teristic frequency (C.F.) remote from the signal frequency. This decrease in excitation primarily occurs in filters with C.F. below the signal frequency because of the steep upper slope of auditory filters. Therefore, to make the excitation pattern for a short tone match as best it can (in the least squares sense) the excitation pattern for a long tone, one needs to increase the frequency of the short tone above that of the long tone. This predicts that the columns in Table 1 should be filled with the symbol S.

\section{APPENDIX \\ Additional Pitch-Matching Experiments}

This appendix reports the results of additional pitch-matching experiments, with different amplitude envelopes (Conditions 1 and 3). It also gives data for a set of matching experiments done in a high-frequency range (Condition 4). The data presented here supplement the data reported in the pitch-matching experiment section above and support the conclusions of the paper. When the pitch-matching experiment was done, the experiment runs were blocked according to the conditions described below. Each subject went through these conditions in a different order.

Condition 1 . The target-tone frequencies were set at 200,342 , 584 , and $1000 \mathrm{~Hz}$. Both target and matching tones had abrupt onsets and offsets, and all tones had the same energy. The tone durations and intensities were: $12 \mathrm{msec}$ at $70 \mathrm{~dB}$ SPL, $25 \mathrm{msec}$ at $67 \mathrm{~dB} \mathrm{SPL}$, and $50 \mathrm{msec}$ at $64 \mathrm{~dB}$ SPL.

Condition 2. This is the condition described as the pitchmatching experiment in the body of this text. Stimulus parameters

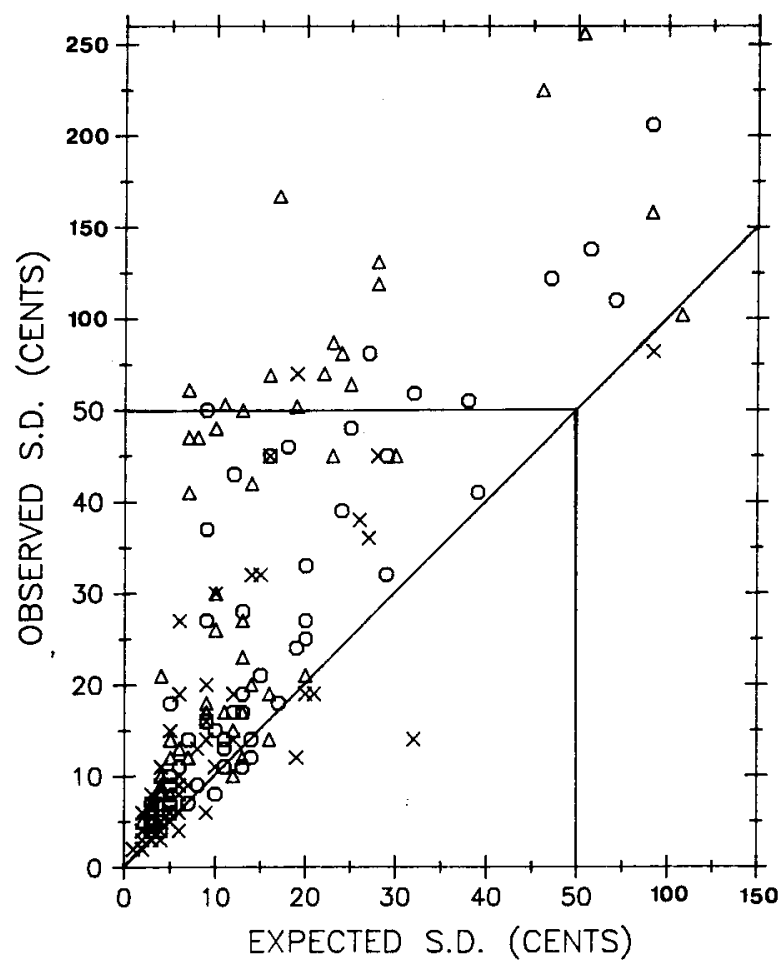

Figure 4. Extended pitch-matching experiment: Observed value of the standard deviation in matching frequencies for tones of unequal duration plotted against the expected value of the standard deviation based upon the standard deviations for tones of equal durations. The expectation is derived from statistical decision theory (see text). All four conditions listed in the Appendix are included. Symbols are the same as in Figure 1. 
Table 4

Standard Deviations of Pitch Matches Made in the Three Additional Conditions of the Extended Pitch-Matching Experiment

\begin{tabular}{|c|c|c|c|c|c|c|c|c|}
\hline \multirow[b]{2}{*}{ Condition } & \multirow[b]{2}{*}{ Subject } & \multirow[b]{2}{*}{$\begin{array}{c}\text { Frequency } \\
(\mathrm{Hz})\end{array}$} & \multicolumn{3}{|c|}{ Equal Durations } & \multicolumn{3}{|c|}{ Unequal Durations } \\
\hline & & & $12 / 12$ & $25 / 25$ & $50 / 50$ & $\begin{array}{l}12 / 25 \\
25 / 12 \\
\end{array}$ & $\begin{array}{l}12 / 50 \\
50 / 12\end{array}$ & $\begin{array}{l}25 / 50 \\
50 / 25 \\
\end{array}$ \\
\hline \multirow[t]{4}{*}{1} & $\mathbf{T}$ & $\begin{array}{r}200 \\
342 \\
584 \\
1000\end{array}$ & $\begin{array}{r}32 \\
19 \\
17 \\
9\end{array}$ & $\begin{array}{r}26 \\
12 \\
8 \\
3\end{array}$ & $\begin{array}{l}7 \\
5 \\
2 \\
2\end{array}$ & $\begin{array}{l}45 \\
21 \\
12 \\
12\end{array}$ & $\begin{array}{l}46 \\
18 \\
11 \\
14\end{array}$ & $\begin{array}{r}13 \\
6 \\
15 \\
7\end{array}$ \\
\hline & B & $\begin{array}{r}200 \\
342 \\
584 \\
1000\end{array}$ & $\begin{array}{r}128 \\
65 \\
10 \\
11\end{array}$ & $\begin{array}{r}18 \\
19 \\
8 \\
8\end{array}$ & $\begin{array}{r}20 \\
10 \\
3 \\
4\end{array}$ & $\begin{array}{r}206 \\
122 \\
37 \\
51\end{array}$ & $\begin{array}{r}158 \\
225 \\
61 \\
47\end{array}$ & $\begin{array}{l}70 \\
32 \\
27 \\
19\end{array}$ \\
\hline & $\mathrm{L}$ & $\begin{array}{r}200 \\
342 \\
584 \\
1000\end{array}$ & $\begin{array}{r}74 \\
24 \\
6 \\
14\end{array}$ & $\begin{array}{r}35 \\
12 \\
4 \\
4\end{array}$ & $\begin{array}{r}17 \\
6 \\
3 \\
2\end{array}$ & $\begin{array}{r}139 \\
46 \\
10 \\
8\end{array}$ & $\begin{array}{r}257 \\
167 \\
10 \\
48\end{array}$ & $\begin{array}{r}36 \\
15 \\
8 \\
4\end{array}$ \\
\hline & A & $\begin{array}{r}200 \\
342 \\
584 \\
1000\end{array}$ & $\begin{array}{r}* * * \\
23 \\
7 \\
5\end{array}$ & $\begin{array}{r}* * * \\
8 \\
4 \\
5\end{array}$ & $\begin{array}{r}* * * \\
5 \\
2 \\
4\end{array}$ & $\begin{array}{r}* * * \\
18 \\
7 \\
9\end{array}$ & $\begin{array}{r}* * * \\
14 \\
8 \\
8\end{array}$ & $\begin{array}{r}* * * \\
7 \\
5 \\
5\end{array}$ \\
\hline \multirow[t]{4}{*}{3} & $\mathrm{~T}$ & $\begin{array}{r}200 \\
342 \\
584 \\
1000\end{array}$ & $\begin{array}{r}21 \\
16 \\
7 \\
5\end{array}$ & $\begin{array}{l}9 \\
5 \\
4 \\
3\end{array}$ & $\begin{array}{l}9 \\
4 \\
2 \\
1\end{array}$ & $\begin{array}{r}45 \\
11 \\
11 \\
5\end{array}$ & $\begin{array}{r}69 \\
17 \\
14 \\
7\end{array}$ & $\begin{array}{r}17 \\
6 \\
4 \\
2\end{array}$ \\
\hline & $\mathbf{B}$ & $\begin{array}{r}200 \\
342 \\
584 \\
1000\end{array}$ & $\begin{array}{r}38 \\
15 \\
9 \\
12\end{array}$ & $\begin{array}{r}18 \\
10 \\
10 \\
6\end{array}$ & $\begin{array}{r}15 \\
11 \\
6 \\
7\end{array}$ & $\begin{array}{l}32 \\
44 \\
27 \\
17\end{array}$ & $\begin{array}{r}131 \\
50 \\
41 \\
10\end{array}$ & $\begin{array}{l}46 \\
30 \\
13 \\
19\end{array}$ \\
\hline & $\mathrm{L}$ & $\begin{array}{r}200 \\
342 \\
584 \\
1000\end{array}$ & $\begin{array}{l}30 \\
30 \\
20 \\
10\end{array}$ & $\begin{array}{r}34 \\
45 \\
5 \\
6\end{array}$ & $\begin{array}{r}17 \\
9 \\
7 \\
4\end{array}$ & $\begin{array}{l}59 \\
56 \\
12 \\
10\end{array}$ & $\begin{array}{c}81 \\
70 \\
20 \\
13\end{array}$ & $\begin{array}{r}38 \\
14 \\
7 \\
5\end{array}$ \\
\hline & A & $\begin{array}{r}200 \\
342 \\
584 \\
1000\end{array}$ & $\begin{array}{r}* * * \\
12 \\
5 \\
4\end{array}$ & $\begin{array}{r}* * * \\
9 \\
6 \\
3\end{array}$ & $\begin{array}{r}* * * \\
5 \\
3 \\
1\end{array}$ & $\begin{array}{r}* * * \\
15 \\
9 \\
6\end{array}$ & $\begin{array}{r}* * * \\
17 \\
9 \\
5\end{array}$ & $\begin{array}{r}* * * \\
10 \\
5 \\
3\end{array}$ \\
\hline \multirow[t]{4}{*}{4} & $\mathbf{T}$ & $\begin{array}{l}2000 \\
4000 \\
7000\end{array}$ & $\begin{array}{r}10 \\
6 \\
14\end{array}$ & $\begin{array}{r}2 \\
4 \\
26\end{array}$ & $\begin{array}{r}3 \\
3 \\
15\end{array}$ & $\begin{array}{r}7 \\
9 \\
27\end{array}$ & $\begin{array}{l}12 \\
21 \\
42\end{array}$ & $\begin{array}{r}4 \\
8 \\
19\end{array}$ \\
\hline & $\mathbf{B}$ & $\begin{array}{l}2000 \\
4000 \\
7000\end{array}$ & $\begin{array}{l}15 \\
33 \\
91\end{array}$ & $\begin{array}{r}6 \\
12 \\
44\end{array}$ & $\begin{array}{r}7 \\
13 \\
123\end{array}$ & $\begin{array}{r}13 \\
39 \\
110\end{array}$ & $\begin{array}{r}53 \\
64 \\
103\end{array}$ & $\begin{array}{l}10 \\
20 \\
82\end{array}$ \\
\hline & $\mathbf{L}$ & $\begin{array}{l}2000 \\
4000 \\
7000\end{array}$ & $\begin{array}{l}17 \\
13 \\
14\end{array}$ & $\begin{array}{r}6 \\
14 \\
23\end{array}$ & $\begin{array}{r}4 \\
6 \\
18\end{array}$ & $\begin{array}{l}17 \\
17 \\
24\end{array}$ & $\begin{array}{l}15 \\
31 \\
19\end{array}$ & $\begin{array}{r}7 \\
12 \\
19\end{array}$ \\
\hline & A & $\begin{array}{l}2000 \\
4000 \\
7000\end{array}$ & $\begin{array}{l}4 \\
5 \\
4\end{array}$ & $\begin{array}{l}3 \\
3 \\
3\end{array}$ & $\begin{array}{l}3 \\
2 \\
2\end{array}$ & $\begin{array}{l}4 \\
4 \\
4\end{array}$ & $\begin{array}{l}7 \\
5 \\
6\end{array}$ & $\begin{array}{l}3 \\
3 \\
3\end{array}$ \\
\hline
\end{tabular}

Note-Values are in cents.

were identical to those of Condition 1 except that all tones were equated in intensity at $70 \mathrm{~dB}$ SPL.

Condition 3. Stimulus parameters were identical to those of Condition 1 except that all tones were turned on and off with raised cosine edges of $6 \mathrm{msec}$ duration. The steady-state durations of the tones were shortened by $6 \mathrm{msec}$ so that each tone had the same energy as the corresponding member in Condition 1 . An edge of $6 \mathrm{msec}$ duration was adequate to remove clicks at onsets and offsets.
Condition 4. Stimulus parameters were identical to those of Condition 1 except that there were only three target-tone frequencies, and these were set at 2000,4000 , and $7000 \mathrm{~Hz}$.

\section{Results}

Pitch shifts. The four subjects, four conditions, three or four target frequencies, and three pairs of target and matching tones of unequal duration $(12-25,12-50,25-50 \mathrm{msec})$ provided 171 cases for an extended study of pitch shifts. The trend indi- 
cated in Table 1 was preserved in Condition 1 , in which the tones had equal energy. Shorter tones have lower pitch for 12-msec-25-msec and 12-msec-50-msec comparisons; longer tones have lower pitch for 25 -msec-50-msec comparisons. In the case of the high-frequency tones in Condition 4 , the longer tone had the lower pitch in 21 out of 30 cases of simple duration dependence, and there was no particular dependence on durations. It is interesting to note that all these points concerning pitch shifts with duration agree with the 70-dB SPL data of Doughty and Garner (1948) (see their Figure 4). In Condition 3, there was no evident trend in pitch shifts. We conclude that the pitch shifts associated with different durations may be rather consistent for a particular condition, but that they are not robust. The pattern of shifts can be broken by a change in the form of the stimulus amplitude envelope. 5

Variability. The SDs for the extended matching experiment are given in Table 4 , which is of the same form as Table 2.
Again, in Table 4, one sees that the SDs for unequal durations tend to be larger than those for equal durations. We made plots, similar to Figure 1, for each condition above, to compare the observed values of the SD for tones of unequal duration with the predicted values of the SD, based upon the values of the SD for tones of equal duration and upon one-dimension decision theory. The only notable difference among the four plots was that observed SDs were somewhat larger for Condition 1 than for the other conditions. The results from all four plots are presented together in Figure 4. Again, it is clear that almost all the data lie above the $45^{\circ}$ line, suggesting that when the tones are of equal duration they are matched along more than one dimension, presumably including a timbral dimension. That Condition 3 , with a raised cosine amplitude envelope, was not different from the conditions with abrupt onsets and offsets suggests that whatever the form of the amplitude envelope, a short tone will have some usable timbral character.

(Manuscript received May 23, 1985;

revision accepted for publication August 27, 1985.) 